\title{
Implementing an Online Student Laboratory Data Repository in a First Year Undergraduate Health Science Course
}

\author{
Craig Engstrom, Michael Bulmer, Peter Newcombe, and Ben Hoffman
}

\begin{abstract}
In many large first year undergraduate courses in the health sciences, students participate in practical sessions (pracs) in which they are taught about and provided with opportunities to practice basic skills and techniques for measuring biophysical and psychological variables. We have successfully developed and implemented an Online Student Laboratory Data Repository in an introductory health science course which provides rich opportunities for using a large, student centric dataset in lecture components of the course to explore and evaluate underlying principles, models and theories within the discipline or profession. In future work we will examine its effectiveness in improving collaboration between undergraduate students from different health science programs.
\end{abstract}

Index Terms-Practical class data, student-centric, online data collation.

\section{INTRODUCTION}

In many large first year undergraduate courses in the health sciences, students participate in small-class (15-30 students) practical sessions (pracs) in which they are taught about and provided with opportunities to practice basic skills and techniques for measuring biophysical and psychological variables (e.g., body mass, height, muscle strength, cardiorespiratory fitness, personality traits, body image etc). In addition to learning profession-specific knowledge and skills, these pracs are also commonly used as a basis for introducing students to elementary statistical analyses which are then often incorporated into dedicated "lab-reports" as a formal course assessment task. Moreover, the collation and consolidation of student-generated data from all prac groups provides rich opportunities to use a large, student centric dataset in lecture components of the course to explore and evaluate underlying principles, models and theories within the discipline or profession. Here, we present how an Online Student Laboratory Data Repository can facilitate the use of prac data from a large cohort of students, generated directly by themselves, within the lecture components of an

Manuscript received September 30, 2015; revised December 2, 2015.

C. Engstrom and B. Hoffman are with the School of Human Movement and Nutrition Sciences, the University of Queensland, St Lucia, Brisbane, 4072 Australia (e-mail: craig@ hms.uq.edu.au,b.hoffman@uq.edu.au).

M. Bulmer is with the School of Mathematics and Statistics, the University of Queensland, St Lucia, Brisbane, 4072 Australia (e-mail: m.bulmer@uq.edu.au).

P. Newcombe is with the School of Psychology, the University of Queensland, St Lucia, Brisbane, 4072 Australia (e-mail: newc@psy.uq.edu.au). introductory undergraduate health science course.

\section{COURSE CONTEXT AND DESIGN OF ONLINE StUdent LABORATORY DATA REPOSITORY}

In the current paper, we look at implementation of an Online Student Laboratory Data Repository in a large, first year course (BIOL1900 - Biophysical Development, Measurement and Assessment) offered through the School of Human Movement \& Nutrition Sciences at The University of Queensland. BIOL1900 aims to provide understanding and analysis of how humans grow and develop with a focus on exercise, health and sport. The course covers introductory materials within the sub-disciplines of human growth and development (auxology), functional anatomy (kinanthropometry), exercise physiology, psychology (developmental) and motor learning. It is a compulsory course for students enrolled in the Bachelor of Exercise and Sports Science and the Bachelor of Health and Physical Education (both 4 year professional degrees) as well as in the Bachelor of Exercise and Nutrition Science (3 year non-professional degree). BIOL1900 is also commonly undertaken as an elective course by students enrolled across a variety of degrees within the university including the Bachelor of Arts, Bachelor of Engineering and Bachelor of Science. Over recent years the course enrolments have ranged between 450-500 students each semester.

BIOL1900 is a traditional on-campus "lecture-laboratory" course offered over a 12 week semester. There are 5 pracs held over the semester involving a series of 2 hour laboratory sessions with $\sim 25$ students per group which require them to perform and record measurements for an array of health-related anthropometric, physiological and psychological variables such as body mass, standing height, body mass index (BMI), waist-to-hip ratio, sit and reach flexibility, maximum vertical jump height, grip strength, resting and exercising heart rate, predicted maximum oxygen consumption $\left(\mathrm{VO}_{2} \max \right)$, body shape rating. Each student then logs onto the BIOL1900 Online Student Laboratory Data Repository using their normal UQ student account to enter their own data, which is de-identified, for inclusion in a tab-delimited text file combined across all prac groups. The Online Student Laboratory Data Repository uses a general mySQL framework to create datasets by listing the variables to be collected, including their type, any limits on values, and the question used to elicit the responses. These are then displayed as forms to the students using PHP and HTML/JavaScript, including checks for valid entries prior to submission. Once the data has been entered, a final script 
collates the responses into a tab-delimited text file which can be exported into any number of statistical software programs
(Fig. 1).

\begin{tabular}{|c|c|c|c|c|c|c|c|c|c|c|c|c|c|c|c|}
\hline \multirow{2}{*}{ Age } & \multirow{2}{*}{$\begin{array}{l}\text { Sex } \\
8 \text { Male }\end{array}$} & \multirow{2}{*}{$\begin{array}{l}\text { Throw } \\
\text { Right }\end{array}$} & \multicolumn{4}{|c|}{ StandingHeig SittingHeight RelativeHeig BodyMass } & BMI & \multirow{2}{*}{\begin{tabular}{ll|} 
Waist & \\
& 78
\end{tabular}} & Hip & \multicolumn{3}{|c|}{ GripStrength GripStrength SitReach } & VerticalJump & dingLon! & \\
\hline & & & 180 & 96 & 53.33 & 70 & 24.69 & & 93 & 54 & 48 & 0 & 67 & 2.45 & 41 \\
\hline 19 & 9 Female & Right & 172.4 & 92.1 & 53.4 & 66 & 22.3 & 71.8 & 95 & 32 & 30 & 53 & 45 & 176 & 48 \\
\hline 17 & 7 Female & Left & 165 & 87.5 & 53 & 58 & 21.3 & 69.3 & 93.3 & 32 & 30 & 26.4 & 49 & 180 & 49 \\
\hline 17 & 7 Male & Right & 181.4 & 96.43 & 53.16 & 77.75 & 23.62 & 81.5 & 98 & 39 & 33 & 49.5 & 60 & 221 & 49 \\
\hline 19 & 9 Male & Right & 178.5 & 92 & 51.5 & 69.5 & 21.8 & 73.5 & 93.5 & 44 & 51 & 16 & 63 & 211 & 50 \\
\hline 18 & 8 Female & Right & 167 & 90 & 53.89 & 61 & 21 & 72 & 92 & 38 & 35.2 & 217.5 & 42 & 155 & 50 \\
\hline 17 & 7 Female & Right & 166.5 & 90.4 & 54.35 & 57 & 20 & 67 & 95.5 & 34 & 29 & 62 & 33 & 148 & 50 \\
\hline 17 & 7 Female & Right & 175.7 & 91.6 & 52.1 & 56.7 & 18.37 & 66.5 & 86.8 & 36 & 30 & 70 & 29 & 1.55 & 53 \\
\hline 18 & 8 Male & Right & 169 & 95 & 56.2 & 58 & 20.3 & 71 & 84 & 36 & 40 & 250 & 61 & 256 & 54 \\
\hline 17 & 7 Female & Right & 163 & 83.5 & 51.23 & 50 & 18.82 & 71 & 80 & 25 & 24 & 25 & 35 & 155 & 54 \\
\hline 17 & 7 Male & Right & 176 & 94.3 & 53.6 & 66 & 21.3 & 76.8 & 92.3 & 35.5 & 35 & 42 & 53 & 223 & 54 \\
\hline 18 & 8 Male & Right & 183 & 86 & 47.1 & 85 & 25.38 & 82 & 88 & 54 & 60 & 30 & 66 & 250 & 56 \\
\hline 26 & 6 Male & Right & 180 & 89.2 & 49.55 & 70.5 & 21.8 & 81.1 & 93.5 & 60 & 49 & 46 & 95 & 330 & 56 \\
\hline 17 & 7 Male & Right & 170 & 90.2 & 52.74 & 75 & 25.01 & 69 & 76 & 60 & 55 & 131.6 & 52 & 2.98 & 59 \\
\hline 18 & 8 Male & Right & 187 & 97.9 & 52.4 & 64 & 18.3 & 71 & 81 & 45 & 41 & 10 & 52 & 195 & 59 \\
\hline 25 & 5 Male & Right & 178.5 & 97 & 54.3 & 76 & 23.9 & 81 & 92.5 & 55 & 55 & 59.5 & 54 & 230 & 60 \\
\hline 26 & 6 Male & Right & 180 & 91.8 & 50.9 & 61 & 18.77 & 70.25 & 73.7 & 51.5 & 49.5 & 130 & 36 & 180 & 60 \\
\hline 20 & 0 Male & Right & 183.5 & 97.1 & 52.91 & 74.5 & 22.12 & 74.8 & 97.7 & 50 & 48.5 & 110 & 70 & 245 & 60 \\
\hline 17 & 7 Male & & 193 & 98 & 50.65 & 85 & 23.46 & 87 & 90 & 54 & 50 & 36 & 55 & 200 & 60 \\
\hline 18 & 8 Female & Right & 167 & 89 & 53 & 65 & 22 & 71 & 84 & 34 & 30 & 40 & 59 & 65 & 60 \\
\hline 17 & 7 Male & Right & 189.5 & 96.8 & 51.1 & 63.8 & 17.8 & 59.5 & 73.45 & 48 & 45 & 43.5 & 80 & 2.54 & 60 \\
\hline 17 & 7 Female & Right & 165.2 & 89.8 & 54.4 & 53 & 19.5 & 67.4 & 91.5 & 31.5 & 29 & 185 & 23 & 210 & 60 \\
\hline 17 & 7 Male & Right & 170.1 & 82.1 & 48.3 & 54 & 18.7 & 59.3 & 69.3 & 58.5 & 54.5 & 85 & 64 & 2.4 & 60 \\
\hline 18 & 8 Female & Right & 167.3 & 91.5 & 54.7 & 75 & 26.9 & 81.3 & 95.5 & 45.5 & 45 & 53.5 & 44 & 200 & 61 \\
\hline 24 & 4 Male & Right & 170 & 95.5 & 55.9 & 84.25 & 29.15 & 88 & 106.5 & 48.5 & 53 & 42 & 57 & 214 & 62 \\
\hline 22 & 2 Female & Right & 166 & 84 & 50.6 & 62 & 22 & 77.5 & 93.2 & 3.7 & 3.1 & 110 & 64 & 170 & 62 \\
\hline 34 & 4 Female & Right & 162 & 92 & 56.7 & 76 & 28.95 & 83.5 & 99.5 & 32 & 28 & 22.5 & 41 & 1.33 & 62 \\
\hline 23 & 3 Male & Left & 169.5 & 92.4 & 54.5 & 61 & 21.2 & 66.25 & 79.5 & 41 & 38 & 83 & 49 & 215 & 62 \\
\hline 17 & 7 Female & Right & 162 & 90 & 55.6 & 51 & 19.4 & 62 & 85.7 & 34 & 33 & 240 & 39 & 150 & 62 \\
\hline 19 & 9 Male & Right & 174.9 & 90.1 & 51.51 & 82 & 26.81 & 91.6 & 106 & 39 & 39 & 8 & 48 & 191 & 63 \\
\hline 18 & 8 Female & Right & 167.6 & 90.2 & 53.8 & 62 & 22.2 & 71.4 & 101.8 & 30.5 & 28.5 & 40.5 & 36 & 160 & 63 \\
\hline 22 & 2 Male & Left & 174 & 90 & 52.7 & 74.5 & 24.6 & 75 & 94 & 46 & 45 & 175 & 60 & 215 & 64 \\
\hline 17 & 7 Female & Right & 174 & 93 & 53 & 60 & 19.8 & 65 & 94 & 42 & 35 & 255 & 49 & 195 & 64 \\
\hline 18 & 8 Female & Right & 161 & 86.5 & 53.73 & 54 & 20.83 & 71.5 & 91 & 40 & 34 & 85 & 41 & 170 & 64 \\
\hline 18 & 8 Male & Right & 194.8 & 99.4 & 52.11 & 87 & 21.56 & 84.1 & 87.8 & 51 & 43 & 21.2 & 66 & 246 & 64 \\
\hline 17 & 7 Female & Right & 171.5 & 92.1 & 53.76 & 60 & 20.4 & 65 & 88 & 37 & 33 & 155 & 49 & 185 & 64 \\
\hline 19 & 9 Female & Left & 168.5 & 88.27 & 52.36 & 66.3 & 23.33 & 70.4 & 103.9 & 40 & 34.5 & 38.7 & 35 & 150 & 65 \\
\hline 18 & 8 Female & Right & 162.8 & 87.9 & 53.9 & 62 & 23.4 & 80.23 & 101.5 & 24.5 & 25.3 & 55 & 31 & 161.7 & 65 \\
\hline 17 & 7 Female & Right & 157.4 & 84.2 & 53.5 & 52 & 21 & 64.4 & 90.6 & 32.1 & 24.3 & 44 & 19 & 121 & 65 \\
\hline 24 & 4 Female & Right & 162 & 93 & 57.44 & 56.5 & 21.8 & 66.5 & 95.5 & 31 & 28 & 305 & 44 & 185 & 66 \\
\hline 18 & 8 Female & Right & 167 & 89 & 53.3 & 65 & 23.3 & 72 & 102 & 30 & 23 & 15.5 & 35 & 160 & 66 \\
\hline 19 & 9 Female & Right & 155.1 & 88 & 56.8 & 54 & 22.48 & 69.5 & 90 & 25 & 24 & 155 & 43 & 145 & 66 \\
\hline 18 & 8 Female & Right & 165.5 & 88.2 & 53.3 & 64.2 & 23.4 & 72.7 & 93.8 & 40.5 & 29.5 & 57 & 25 & 180 & 66 \\
\hline 17 & 7 Female & Right & 168 & 88.26 & 52.5 & 69 & 24.5 & 72.6 & 99.91 & 31 & 27 & 10 & 36 & 1.45 & 66 \\
\hline 17 & 7 Female & Right & 172.1 & 89.1 & 51.8 & 60 & 20.3 & 69.9 & 91.6 & 32.5 & 26.5 & 38.7 & 33 & 170.5 & 66 \\
\hline 18 & 8 Male & Right & 180 & 91.5 & 50.83 & 76 & 23.45 & 76.4 & 95.5 & 49 & 44 & 80 & 62 & 245 & 66 \\
\hline 19 & 9 Male & Right & 185.5 & 101.8 & 56 & 85.1 & 24.6 & 79.5 & 83.5 & 57.5 & 52.5 & 145 & 59 & 178 & 67 \\
\hline 29 & 9 Female & Right & 168 & 86.6 & 51.54 & 52.5 & 18.6 & 67.3 & 91.2 & 24.5 & 21.5 & 85 & 29 & 33 & 67 \\
\hline 18 & 8 Male & Right & 176.8 & 94.3 & 53.3 & 71.5 & 22.9 & 79 & 93 & 61.5 & 55.1 & 46.5 & 58 & 210 & 67 \\
\hline 18 & 8 Male & Right & 183 & 95.5 & 52.2 & 67 & 19.6 & 70 & 96 & 48 & 40 & 95 & 62 & 220 & 67 \\
\hline 17 & 7 Female & Right & 162.8 & 88.2 & 54.18 & 52.3 & 19.73 & 19.8 & 27.9 & 20.4 & 20.4 & 230 & 26 & 115 & 67 \\
\hline 17 & 7 Female & Right & 165 & 87 & 52.7 & 62 & 22.8 & 75.5 & 98 & 34.5 & 27 & 85 & 45 & 195 & 67 \\
\hline 18 & 8 Male & Right & 184 & 95 & 51.58 & 79 & 23.3 & 80 & 96 & 57.5 & 46 & 36 & 68 & 212 & 67 \\
\hline 18 & 8 Male & Right & 167.1 & 88 & 52.66 & 61 & 21.86 & 76.5 & 90 & 39 & 37 & 40 & 52 & 206 & 67 \\
\hline 19 & 9 Female & Right & 173.5 & 90.2 & 52 & 53.3 & 17.6 & 67.5 & 93.5 & 32 & 29 & 37 & 45 & 180 & 68 \\
\hline 23 & 3 Male & Right & 169.3 & 89 & 52.56 & 48 & 16.74 & 60.5 & 85.5 & 32.5 & 29.5 & 6.4 & 28 & 125 & 68 \\
\hline 17 & 7 Male & Right & 180.9 & 95.5 & 52.8 & 100 & 30.58 & 87.5 & 86.5 & 48 & 50 & 140 & 50 & 190 & 68 \\
\hline 17 & 7 Female & Right & 171.5 & 90.5 & 52.8 & 60 & 20.4 & 66 & 93 & 34 & 32 & 53.5 & 47 & 196 & 68 \\
\hline 17 & 7 Female & Right & 176 & 88.5 & 50.3 & 64 & 20.6 & 76.3 & 88.83 & 29.3 & 23.6 & 35 & 33 & 173.3 & 69 \\
\hline 20 & 0 Female & Right & 174.7 & 91.1 & 52.1 & 67.8 & 22.2 & 84.5 & 98.5 & 39 & 36 & 47.5 & 47 & 175 & 70 \\
\hline 20 & 0 Male & Right & 180 & 93.7 & 52.1 & 74 & 22.8 & 25 & 96.8 & 55.5 & 54.5 & 57 & 82 & 265 & 70 \\
\hline 18 & 8 Female & Right & 167 & 91.5 & 54.49 & 63 & 22.59 & 70.5 & 98.5 & 34 & 38.5 & 60 & 38 & 207 & 70 \\
\hline 17 & 7 Female & Right & 159.3 & 89.86 & 56.28 & 54.5 & 21.29 & 65.33 & 90.33 & 36 & 32.5 & 310 & 48 & 180 & 70 \\
\hline 17 & 7 Female & Right & 162 & 88.9 & 54.88 & 61.5 & 22.61 & 70.83 & 100 & 32.5 & 27.5 & 36.73 & 36 & 120 & 70 \\
\hline 18 & 8 Male & Right & 179.5 & 93.1 & 51.9 & 63 & 19.44 & 68.25 & 83.5 & 41 & 40 & 25 & 50 & 185 & 70 \\
\hline 19 & 9 Female & Right & 167.3 & 91.5 & 54.7 & 75 & 26.9 & 81.3 & 95.4 & 45.5 & 45 & 53.5 & 44 & 200 & 71 \\
\hline
\end{tabular}

Fig. 1. Screen-shot of the tab-delimited text file containing a sample of the prac data measured and entered by the students.

In the latest implementation of the BIOL1900 Online Student Laboratory Data Repository, $\sim 85 \%$ of the students entered data into the system.

\section{Use of StUdent Collected Prac DAtA IN LECTURE COMPONENTS OF BIOL1900}

One of the important aims in the development and implementation of our current Online Student Laboratory Data Repository is to actively promote the inclusion of the students' own prac data in the lecture components of BIOL1900 to enhance the "personal relevance" to and "engagement" of students with these materials. Here we present illustrative examples related to kinanthropometry (grip strength) and psychology (body image) topics within BIOL1900.
A. Allometric Scaling of Maximum Isometric Grip Strength

Research into the association between muscle strength and body mass has had a major focus on allometric scaling [1]-[3] based around the equation

$$
y=a x^{2 / 3}
$$

where $y$ is muscle strength, $a$ is a scaling coefficient, $x$ is body mass and $2 / 3(b)$ is the scaling exponent.

Biologically, this allometric scaling is based around experimental studies demonstrating that the force (strength) a muscle $\left(F_{m}\right)$ can produce is directly proportional to its cross-sectional area (CSA),

$$
F_{m} \propto \mathrm{CSA}_{m}
$$

Along the same lines,

$$
F_{m} \propto \text { (body) } \text { mass }^{2 / 3}
$$


For example, in Olympic weight-lifters, Challis [1] has reported an allometric relationship between strength (maximum weight lifted) and body mass with a mean scaling exponent of 0.64 (95\% CI: 0.51-0.78). Consistent with the literature, there is an underlying allometric relationship between maximum isometric grip strength and body mass for the male student data in BIOL1900 (Fig. 2), demonstrating a mean scaling exponent of 0.60 . In conjunction with companion data available across all prac sessions for the students (e.g., type of sport/s played, competition level, predominant training mode etc), various sub-analyses can be explored to examine particular groups of students as for the strength trained athletes highlighted in Fig. 2.

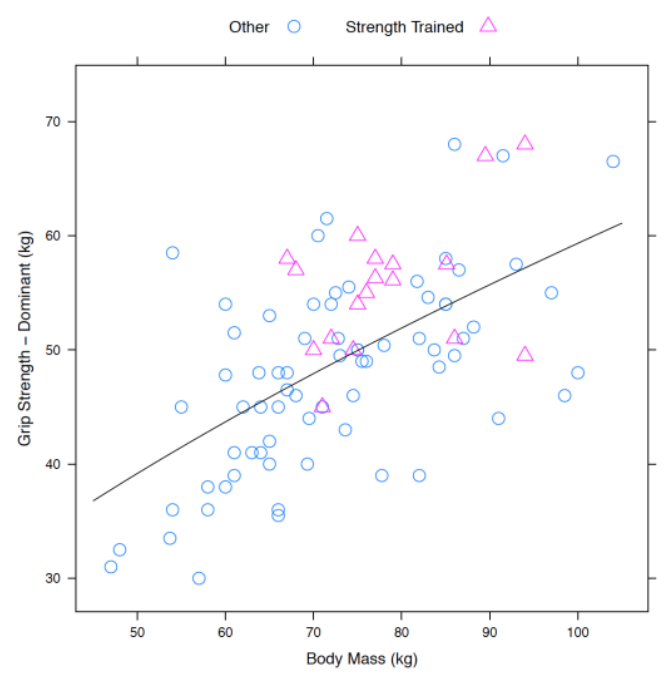

Fig. 2. Allometric scaling of grip strength (dominant hand) and body mass in male students (strength-trained individuals highlighted).

\section{B. Grip Strength Differences between Dominant and Non-dominant Hands}

Clinically, a general "rule" proposing, that on average, the dominant hand is $10 \%$ stronger than the non-dominant hand seems to have been adopted since the mid 1950's although recent studies have reported that the mean difference between maximum dominant and non-dominant grip strength is below this $10 \%$ threshold [4]. Moreover, it has been reported that the mean difference between dominant and non-dominant grip strength in left-handers is comparatively smaller than in right-handers [5]. In comparison with the research literature, the BIOL1900 data for the mean difference between the dominant and non-dominant isometric grip strength is around $7 \%$ and $10 \%$ for male and female students, respectively (Fig. $3)$. There was no evidence of a comparatively smaller difference between the mean dominant and non-dominant grip strength for left-handed subjects (in comparison with the right-handed subjects) in the current student data. In evaluating comparisons between the dominant and non-dominant grip strength data, it must be noted that there is considerable variability in contralateral strength differences across individuals. This suggests that when using grip strength data, clinicians must be cautious when using the ' $10 \%$ rule' to make comparisons between injured and uninjured hands.

\section{Current Body Image Rating and BMI}

The body image data gathering is based on Fallon and Rozin [6]. Students are presented with nine numbered body shape images of increasing size of their own sex (see Fig. 4). After entering age and sex data, the students then respond to 4 questions related to the images - which figure best represents their 1) current, 2) ideal and 3) most attractive to the opposite sex and 4) most attractive in the opposite sex body shape.

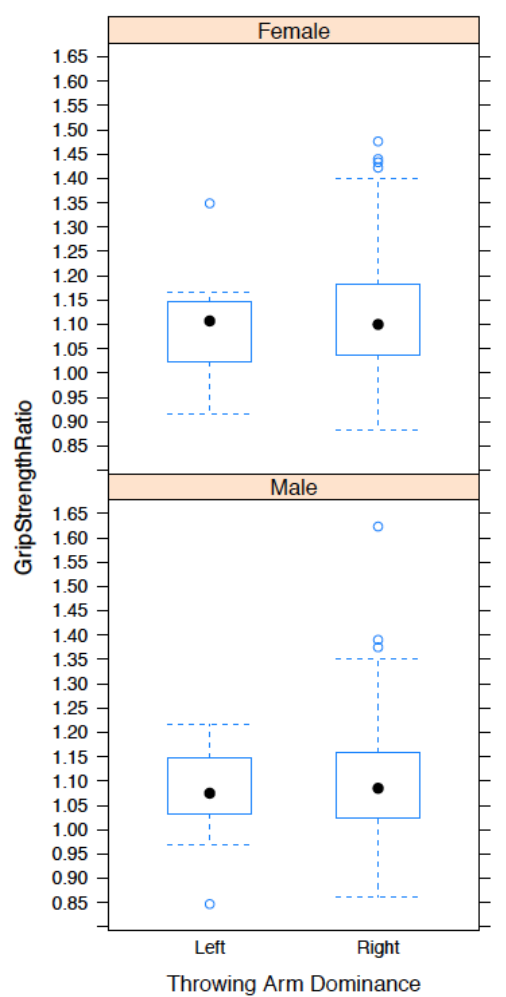

Fig. 3. The ratios between dominant and non-dominant grip strength for left and right-handed female and male students.
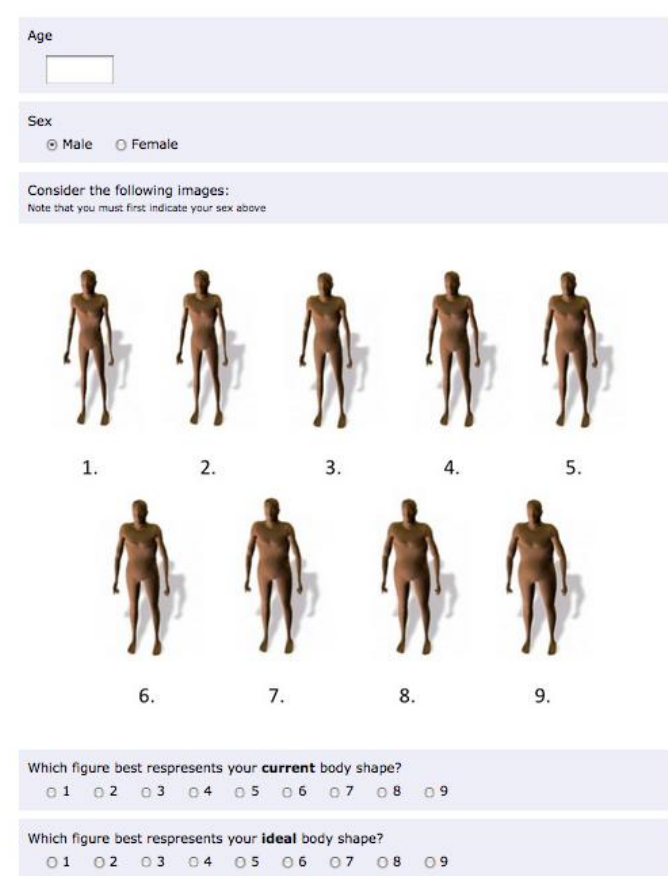

Fig. 4. A screen shot of the nine male body shapes presented to male students.

The BMI data for a student is derived from their measurement of their body mass and standing height based on the following equation:

$$
B M I=\frac{\text { Body Mass }(\mathrm{kg})}{\text { Height }(\mathrm{m})^{2}}
$$

With the students in class, the data can first be presented 
for visual inspection before any inferential analyses are explored. This helps them to better understand the data and its relationships without relying on the "click and flick" of computer analyses. In line with this approach and viewing Fig. 5, the students are able to visualise the relatively good correspondence between self-perceptions of current body shape and the objective measure of BMI. They can also be directed to the marked sex differences with the female data showing greater variability at higher ratings of current shape and an association with BMI that is not as strong as males.

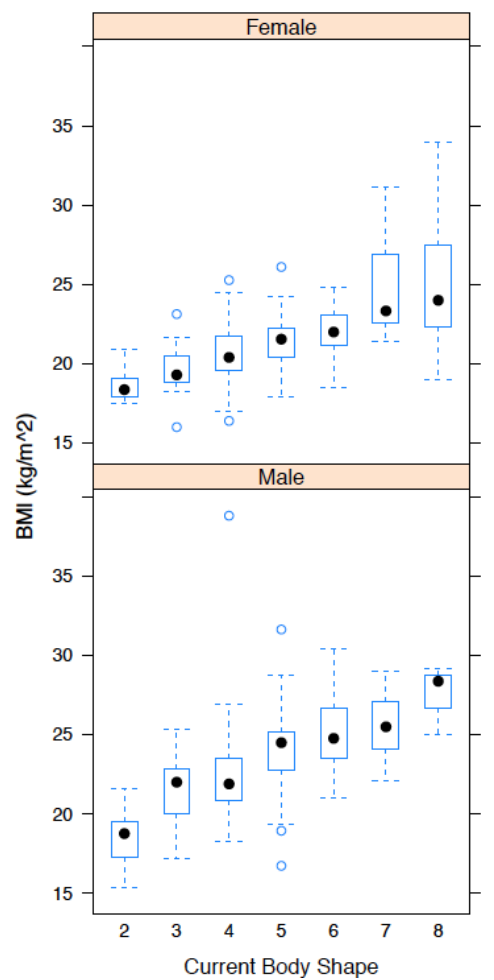

Fig. 5. Perceptions of current body shape plotted against measured BMI for male and female students.

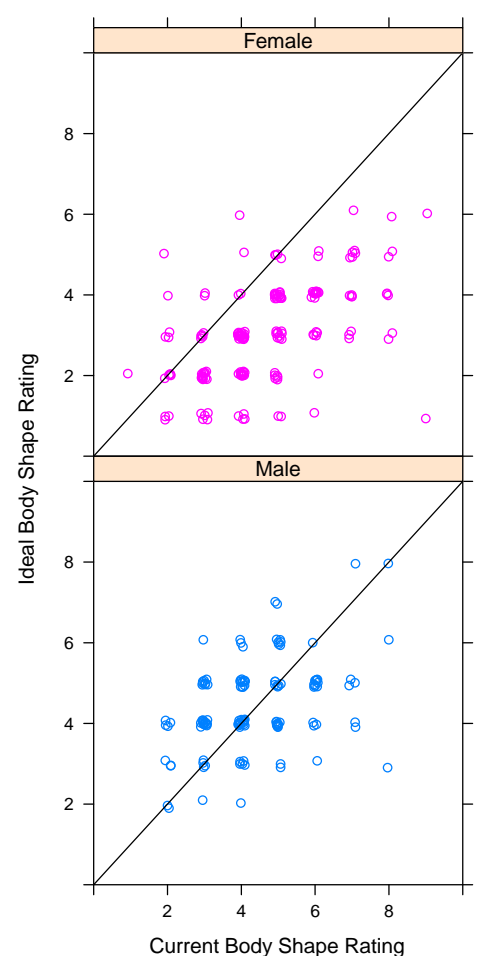

Fig. 6. Scatter plot of the association between perception of current and ideal body shapes for male and female students.

\section{Gender Differences in Perceptions of Body Image}

The student data shown in Fig. 6 and Fig. 7 below demonstrate striking evidence of sex differences in body shape perceptions and are consistent with studies by Fallon and Rozin [6] and others [7]. Fig. 6 demonstrates visually that females tend to rate their current body shape as greater than their ideal body shape (majority of data points below the main diagonal) while for males, this is clearly not the case (data points evenly spaced around the main diagonal).

A similar conclusion can be gained by having the students visually inspect the graphs in Fig. 7 that depict current shape against the shape they believe is attractive to the opposite sex with females rating their current body shape as larger than they expect would be attractive to males.

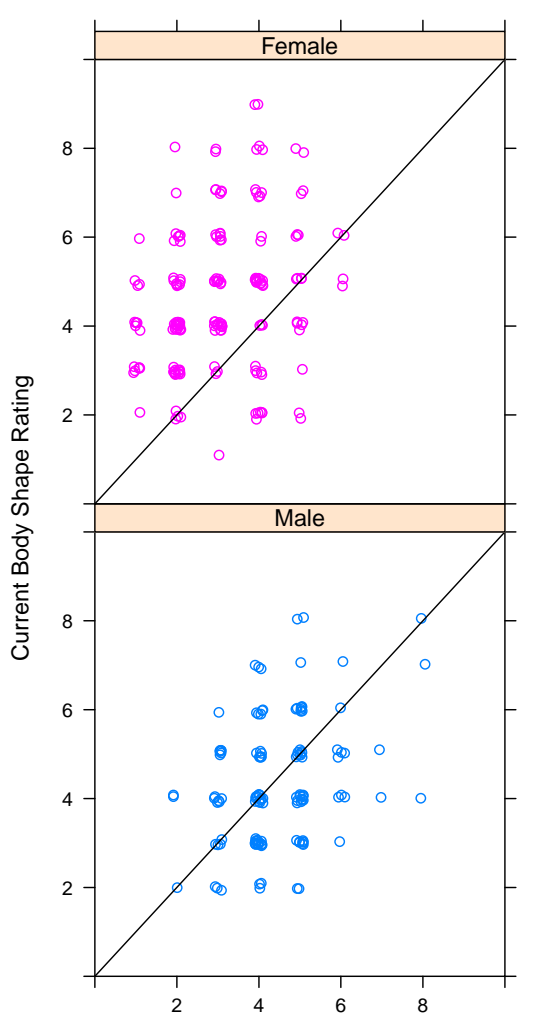

Attractive to Opposite Sex Body Shape Rating

Fig. 7. Scatter plot of the association between perception of current and attractive to opposite body shape rating for male and female students.

\section{DISCUSSION}

\section{A. Current Outcomes}

We have successfully developed and implemented an Online Student Laboratory Data Repository to facilitate the use of prac data from a large cohort of undergraduate students, generated directly by themselves, within the lecture components of an introductory health science course. This approach targets the inclusion of the students' own data in lectures to enhance the "personal relevance" to and "engagement" of students with these materials. It seeks to bring data to "life" for the students and therefore offer a more meaningful (authentic) experience when exploring data analyses and interpretation in lectures. In the current paper, we illustrate how the prac data derived from and by a large cohort of undergraduate students can be readily analysed within the context of the research literature in fields such as kinanthropometry (body mass, grip strength) and psychology 
(body image).

Our Online Student Laboratory Data Repository uses a general mySQL framework to create datasets which are then displayed as forms to the students using PHP and HTML/JavaScript. This online system is simple and easily accessed, as attested to by the high proportion of students $(\sim 85 \%)$ actually entering their data into the central repository. In comparison with a "traditional" distribution and collection of datasheets by the tutors across multiple prac sessions or direct data entry by the students into multiple small (or unwieldy, large) multi-user spreadsheets (with "open" editing functions), the developed system provided a highly efficient scheme for data entry, collation and distribution for the students enrolled in the large BIOL1900 course. This online system automatically output the prac data in a tab-delimited text file which can be exported into any number of spreadsheet or statistical software programs to provide maximum flexibility for the students.

An important aim for the development of our Online Student Laboratory Data Repository is to promote the analysis and discussion of large data sets, collected by the students themselves, to examine key concepts that are covered in lectures (e.g., for understanding measures of muscle strength within basic biological and clinical contexts; the influence of "popular" media on perceptions of body image, eating disorders and the sex differences in current vs ideal body shape perceptions). More generically, the implementation of our system is well-suited for examining and discussing central statistical concepts relating to topics covered in many practical-based, health science courses such as sampling and measurement variability.

\section{B. Future Outcomes}

There is tremendous potential to extend the development and use of our current Online Student Laboratory Data Repository. For example, one obvious avenue is to continue to enhance and implement this system in BIOL1900 over a number of years to investigate longitudinal patterns and relationships in the prac data acquired by successive cohorts of students. Specifically, these data could be used readily in lectures as a basis to compare cross-sectional and longitudinal analyses of kinanthropometric, exercise physiology, motor learning and psychological measures acquired from students in this large undergraduate course. Similarly, the Online Student Laboratory Data Repository could be easily incorporated across multiple courses and programs (degrees) within the current university setting to encourage shared (collaborative) learning opportunities for students thereby exposing them to an inherently interdisciplinary experience in their undergraduate studies. Moreover, the pooling of prac data across cohorts and across courses will enable students to be exposed to a broader range of peer-derived data in their classes (lectures, practicals) and allow students to engage with larger data sets and introduce them to more sophisticated tools for data exploration and analysis.

Within a given academic program, integration of the Online Student Laboratory Data Repository across all year levels would provide a powerful model to analyse the acquisition of technical (practical) skills in students (e.g., measurement accuracy, reliability etc) critical for the development of professional knowledge and competencies. Across programs (degrees), the Online Student Laboratory Data Repository could serve as a potential mechanism to allow for enhanced quality control across large numbers of courses involving practical components. Indeed, such a central online repository offers a powerful model for improved communication and collaboration across courses and programs. Moreover, the capacity of the current online system could be readily expanded to include other data types from students such as video demonstrations of their practical skills to facilitate learning and assessment approaches [8].

\section{CONCLUSION}

We developed and implemented an Online Student Laboratory Data Repository for a first year undergraduate course in the health sciences to promote the use of a large, student centric dataset in lecture components of the course to explore and evaluate underlying principles, models and theories within the discipline or profession. The potential uses and advantages of this system are varied and future research opportunities include investigating its effectiveness in improving collaboration between undergraduate students from different health science programs and, more generally, across numerous academic programs within a university environment.

\section{REFERENCES}

[1] J. H. Challis, "The appropriate scaling of weightlifting performance," The Journal of Strength \& Conditioning Research, vol. 13, pp. 367-371, 1999.

[2] S. Jaric, S. Radosavljevic-Jaric, and H. Johansson, "Muscle force and muscle torque in humans require different methods," European Journal of Applied Physiology, vol. 87, pp. 304-307, 2002.

[3] P. M. Vanderburgh, M. T. Mahar, and C. H. Chou, "Allometric scaling of grip strength by body mass in college-age men and women," Research Quarterly in Exercise \& Sport, vol. 66, pp. 80-84, 1995.

[4] C. A. Armstrong and J. A. Oldham, "A comparison of dominant and non-dominant hand strengths," Journal of Hand Surgery (British and European Volume), vol. 24, pp. 421-425, 1999.

[5] T. Petterson, G. P. Smith, J. A. Oldham, T. E. Howe, and R. C. Tallis, "The use of patterned neuromuscular stimulation to improve hand function following surgery for ulnar neuropathy," Journal of Hand Surgery (British and European Volume), vol. 19, pp. 430-433, 1994.

[6] A. A. Fallon and P. Rozin, "Sex-differences in perceptions of desirable body shape," Journal of Abnormal Psychology, vol. 94, pp. 102-105, 1985.

[7] J. R. Grossbard, N. Clayton, and M. E. Larimer, "Perceived norms for thinness and muscularity among college students: What do men and women really want?" Eating Behaviors, vol. 12, pp. 192-199, 2011.

[8] P. J. Hay, C. Engstrom, A. Green, P. Friis, S. Dickens, and D Macdonald, "Promoting assessment efficacy through an integrated system for online clinical assessment of practical skills," Assessment \& Evaluation in Higher Education, vol. 38, pp. 520-535, 2013.

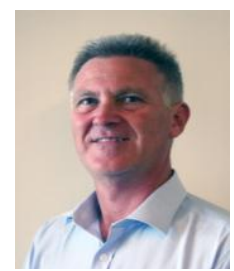

Craig Engstrom is currently a senior lecturer in the School of Human Movement and Nutrition Sciences, the University of Queensland, Australia. He teaches across introductory and advanced level undergraduate courses in the field of exercise and sports medicine and he is the coordinator of the master of sports medicine program. He has undertaken and published research related to the online clinical analysis of clinical skills, web-based multimodal feedback for student lab write-ups and interprofessional education involving experiential learning through exercise programs. 
Michael Bulmer is a senior lecturer in mathematics and statistics at the University of Queensland. His research interests include statistical computing and optimization algorithms, and student learning in higher education. He has extensive experience in engaging diverse student interests in large classes through student-centred curricula. $\mathrm{He}$ has received an Australian Award for University Teaching and a Fellowship from the Australian Learning and Teaching Council.

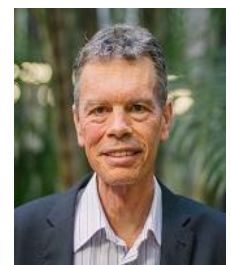

Peter Newcombe is an associate professor in School of Psychology at the University of Queensland, Australia. He teaches introductory and developmental psychology as well as research methodology and has been recognized for his excellence in teaching. His primary research interest concerns quality of life issues in young people with chronic medical and physical conditions. He has co-authored 10 chapters in edited books and published over 60 journal articles as well as over 80 presentations at domestic and international conferences.
Ben Hoffman is currently a lecturer in the School of Human Movement and Nutrition Sciences, the University of Queensland, Australia. He teaches introductory human motor control and completed a Graduate Certificate in Higher Education in 2013. He is also currently the coordinator of the Tutor Development Program within the School of Human Movement and Nutrition Sciences. 